\title{
The Research about the Development Direction of Outdoor Sports in the Perspective of "Healthy China"
}

\author{
Ge Liu \\ Northwest University,shaanxi Xi 'an,710127 \\ 1950899843@qq.com
}

Key Words: "Healthy China”; outdoor sports; public health; research of outdoor sports actuality

\begin{abstract}
In the perspective of "Healthy China" and the interactive relation between health and outdoor sports, the thesis analyses the developing actuality of outdoor sports, knowing clearly about the current situation of people in our country, which aims to make the main thought of the standard of our health, and promote the development of outdoor sports.

There is always a topic in the human history---health. And it is also an important symbol in the social development. In 2015, Premier Li Keqiang came up with "Healthy China" concept firstly in the government report. With the release of the party's bulletin of the Fifth Session of the eighteenth Central Committee of the Party, the new concept---“healthy China”, was brought out to people's life. On October 25th, 2015, the State Council of the PRC printed and distributed the "Healthy China 2030" plan. In this plan, there is a deployment about people's healthy in fifteen years. For this objective---the realization of national health and healthy China, it is necessary for us to strengthen physical exercise. Outdoor sports is a good way to back to nature and enhance our physical fitness. In addition, the idea of healthy life (root in the outdoor sports) accord with the "Healthy China" concept. Therefore, the article is a research about the developing direction of outdoor sports in the perspective of "Healthy China".
\end{abstract}

\section{The Definition and Types of the Outdoor Sports}

China is not the root of outdoor sports. There was not an exact agreed definition of outdoor sports. It was just a new sport.

It was a long time later when the specialists determined a definition for the outdoor sports. After years of the academic discussion, the concept of outdoor sports was gradually defined. The relevant scholars, represented by Ma Jingang, gave a definition for outdoor sports. That is : "various sports and leisure ways backing to nature”. At present, the common concept for outdoor sports is these sports items, which have the characters of adventure in natural environment. The main three categories including water, land and air. According to the definition, the outdoor sports could be divided into six items: mountaineering, rock climbing, orienteering, diving, sailing and drifting, etc. There are various outdoor sports on land in our country. Most of them are aquatic items, such as swimming, drifting, diving and yacht.

\section{The Definition of "Healthy China”}

\section{The Meaning of "Healthy China”}

"Healthy China" is an innovative developing theory. And the core is that overall development of healthy first. "Healthy China" is a new mode of thinking basing on solving the Chinese healthy problems at present and in future. The purpose is to solve the highlight problem of people, so as to realize the final goal of creating healthy China.

\section{The Actuality of Health Development in China}

The 17th National Congress of the Chinese Communist Party states that "Health is the foundation of comprehensive development and the well-being of thousands of families.” Moreover, 
The 18th National Congress of the Chinese Communist Party states that " Healthy is the essential requirement of promoting the all-round development of human beings and the symbol of the country's prosperity. Xi Jinping, General Secretary of the CPC Central Committee mentioned "without national health, there is no overall prosperity" ,which stresses the importance of national health. However, there are still some gaps and challenges between the ultimate goal of the "Healthy China" and the actuality. At present, our country is a high-growth country with cancer, and one person dies every fifteen seconds because of cancer. And the mortality rate for chronic disease rose from $73.8 \%$ in 1991 to $85 \%$ in 2011. At this rate, the number of the chronic disease in our country will increase from two or three times over in the 20 years. Hence, it is a brook no delay task to improve the national health and build "Healthy China” in China's development in future.

\section{The Development of China's Outdoor Sports in the Perspective of "Healthy China"}

A. "Healthy China" is a Chance that it is Good for the development of outdoor sports

During the 13th Five-Year Plan period, with the boost phase of the economy and continuous rising of per capita consumption levels, people pay more attention to the health and the physical quality. So the national emphasis of health gradually enhanced, everyone wants to keep fit. Therefore, outdoor sports develop rapidly from then.

B. The Actuality of Outdoor Sports

\section{Lack of Outdoor Professionals}

According to the research, there are so many outdoor sports clubs and members joining in the climbing. But the problem is lack of outdoor specialists. Some of guides have plentiful outdoor experiences. While other guides are short of the practical experiences, they have less safety awareness of outdoor sports.

At present, most of the outdoor training are the training courses in Chinese Mountaineering Association. But the training course also has its weakness. People still grasps less applied experiences after the training. So it isn't enough for dealing the actual problems just to undergo the training.

\section{Members' Shortage in Favorable Professional Skills}

With the number of outdoor sports persons is continuous increasing, but sad to say, the accidents get more and more. So people's safety is the main concerned problem. According to the data in the White Paper on China's Mountaineering Outdoor Sports accidents, in 2017, 29 people died, 12 wounded, 400 died in the severe accidents. In 2008, 20 died in the outdoor sports. In 2009, 44 people died in a mountaineering accident. Even though too many accidents happened in the outdoor sports, there are still a number of people take part in the sports. Facing so many accidents, we must take the reasons, which cause these accidents, into consideration and find out the solution. It is clearly that the shortage of risk awareness and the management system of outdoor sports are two causes. All in all, people who join outdoor sports lack abundant special experiences and outdoor ability, which is the main cause.

\section{Training of Outdoor Professionals with School Resources}

In order to promote the goal of "Healthy China" further, we should take the training of outdoor specialists into consideration. In August, 2002, Ministry of Education promulgated the "Physical Education Curriculum Guiding Outline for Common Institutes of Higher Learning in China" and declared: "make full use of natural conditions, such as river, lake, sea, mountain, beach and field, to carry out the wild survival activities.” The activities are not only could promote students' physical fitness, but also the development of society.

In addition, the effective development of outdoor sports is also a necessary supplement to the university sports related courses. Lots of colleges lack teaching resources in sports because of the expansion of universities and colleges. It's no doubt that many universities and colleges are behindhand in sports facilities and the playground. The target of outdoor sports is to use natural 
conditions to carry out the related activities, which could relieve the shortage of teaching resources for universities, and enhance students' health.

\section{The Development of Health and Sports under "Healthy China"}

On September 22th, 2016, YiXing held the BBS of "Mountain Outdoor Sports Recreation and Healthy China". Many scholars at home and abroad discussed with the idea of "Mountain Tourism, Green Movement, Synthetic Development”. Here are the points:

China is in an All-sided Outdoor Health State

Our land has vast territory and abundant resources, including mountains, plains, hills, deserts, rivers and ocean resources and so on, so China is fit for outdoor sports. The "Chinese Mountain Outdoor Industry Development Planning (2016-2025)” (The plan is being made)shows that China will build 3000 artificial climbing venues, 3000 natural rock climbing routes, 10000 outdoor camps, 100 outdoor towns and 1000 outdoor sports parks in 10 years. Outdoor sports professionals will increase about 200,000 in future. By 2025, the total sum of China's related outdoor industry's will reach 1 trillion yuan.

Rock Climbing---The Main Resource in the Future Tourism Development

Rock climbing has changed a lot in the past years. It's an X-sports. More and more people start to join the rock climbing. With the natural conditions, the natives could start the tourism project on rock climbing to accelerate native rate of the economic.

\section{The Development of Outdoor Supplies Market in "Healthy China”}

According to the COA statistics, over 130 million people take part in the outdoor sports, and more than 60 million people join in the rock climbing or other X-sports. In 2015, the size of China's outdoor sports market is about 45.4 billion yuan, which rose $12.5 \%$ year-on-year. Our outdoor sporting products market will grow more with the trend.

Under "Healthy China", the major reasons of outdoor sports developing rapidly in China are: the promotion of health awareness, China owns abundant natural resources, which provide basis for outdoor tourism. Our rapid development of economy, which could provide foundation for the outdoor sports. At present, our government is for the national health.

There are a number of chances for supporting outdoor sports, for example, marathon, outdoor ice and snow sports and island sports, etc. With the "Healthy China" strategic rising, the marketization reform of dividend and the growth of the national consumption level, China's outdoor sports have been in the pivotal period. Outdoor sports will be more prosperous in future.

\section{Conclusion}

The thesis analysis China's outdoor sports in the perspective of "Healthy China", and put forward the development direction. Combine the two sides well, the idea of "Healthy China" could be integrated into the development of outdoor sports. In the new period, knowing about our policy could contribute to the construction of healthy China. Our country hasn't made the goal of national health come true, but with the development of outdoor sports, the improving of health awareness, the construction of healthy China will advance continuous.

\section{References}

[1]. A.M. Feng. The Influence of "Healthy China" Strategy on the Sunshine Sports in Colleges and Universities [J]. Wushu Studies, 2017,(02):111-113.

[2] S. P. Zhou. Analysis of the Trend of National Fitness Campaign from the Planning Outline of "Healthy China 2030" [J]. Journal of Nanjing Sport Institute (Social Edition), 2017,(01):59-63+69.

[3]G.Q. Peng, S, F, Shu. The United States Sports Promote Health Service System and Its 
Revelation for the "Healthy China" [J]. Journal of Sports and Science, 2016, (05) : 112-120.

[4]Y, Ma, B, Ding, X , Li, H, Y, Wang and J, M, Zhang. The "Health China" strategy has the enlightenment to the college sunshine sports movement.[J]. Contemporary Sports Technology, 2015, (29):11-12.

[5]. Strengthen children's physique, school together- — Healthy Chinese children sports quality open" and Beijing Sport University support Northeast Center Primary School Sports characteristic development project listing ceremony was officially launched[J]. Youth Sports, 2014,(10):2+12. 